\title{
The Impact of COVID-19 on a Tertiary Care Pediatric Emergency Department
}

\author{
llaria Liguoro ( $\square$ ilarialiguoro@gmail.com ) \\ Department of Medical Area - DAME - Division of Pediatrics, University of Udine, Udine, Italy \\ Chiara Pilotto \\ Department of Medical Area - DAME - Division of Pediatrics, University of Udine, Udine, Italy \\ Michela Vergine \\ Department of Medical Area - DAME - Division of Pediatrics, University of Udine, Udine, Italy \\ Anna Pusiol \\ Department of Medical Area - DAME - Division of Pediatrics, University of Udine, Udine, Italy \\ Enrico Vidal \\ Department of Medical Area - DAME - Division of Pediatrics, University of Udine, Udine, Italy \\ Paola Cogo \\ Department of Medical Area - DAME - Division of Pediatrics, University of Udine, Udine, Italy
}

\section{Research Article}

Keywords: Covid-19, pediatrics, infectious disease, pandemic, emergency care

Posted Date: August 11th, 2020

DOl: https://doi.org/10.21203/rs.3.rs-54932/v1

License: (c) (i) This work is licensed under a Creative Commons Attribution 4.0 International License. Read Full License

Version of Record: A version of this preprint was published at European Journal of Pediatrics on January 7th, 2021. See the published version at https://doi.org/10.1007/s00431-020-03909-9. 


\section{Abstract}

Restricting measures required to face the recent outbreak of a novel Coronavirus (CoV-2) may also impact on patterns of healthcare utilization. Our aim was to provide an insight into the changing use of a pediatric Emergency Department (ED) during the CoV-2 pandemic.

Medical records of children seen in our Pediatric ED during March and April 2020 were retrospectively reviewed. Comparisons with the same time intervals in 2018 and 2019 and with other seasonal control periods (January-February 2019 and 2020, and July-August 2018-2019) were performed.

The total number of ED visits declined of 73\% from 2019 to 2020 (3051 vs 818). Significant variations were observed in the distribution of children among triage categories: the proportion of cases scored as green-code showed a 0.59 -fold decrease in comparison to 2019 (95\% Cl 0.5-0.69), while a relative increase in the proportion of yellow codes was observed (OR 1.46, 95\% $\mathrm{Cl} 1.2-1.78$ ).

Conclusion: Quarantine measures significantly impacted on the total number and reasons for visits in our Pediatric ED. This substantial decrease in pediatric care access may be either due to lower rates of acute infections because of social distancing, and to reticence on the part of parents and caregivers to risk exposure to SARS-CoV-2 in a health-care setting.

\section{Introduction}

A novel type of Coronavirus (CoV) was recently identified in subjects affected by pneumonia of unknown origin in Wuhan (China)(1). The virus was named Severe Acute Respiratory Syndrome Coronavirus-2 (SARS-CoV-2) and the associated disease has been called 2019 Coronavirus Disease (COVID19)(2). SARS-CoV-2 rapidly spread worldwide, forcing the World Health Organization (WHO) to recognize the outbreak as a pandemic on 11 March, 2020(3).

Italy was among the first countries to be hit in the world, with a large number of COVID-19 cases(4). On the $8^{\text {th }}$ of March the Italian Government imposed a national quarantine, restricting the movement of all citizens except for necessity, work, and health circumstances, in response to the growing pandemic of COVID-19 in the country. Social distancing has been proven to be effective in lowering the incidence of new SARS-CoV-2 infections (5,6). However, restricting measures may also impact on several social and economic aspects of people's routine life(7), in particular on patterns of healthcare utilization, as observed in other previous infectious disease outbreaks $(8,9)$.

As largely described, Emergency Departments (ED) services are usually overwhelmed by an inappropriately heavy access for not urgent conditions, ranging from 24 to $40 \%$ of total visits(10). Reasons for this behavior may be identified in accessibility problems with the primary care provider (PCP)(11), and in the parents' misperception of the severity of the illness(12). However, some recent preliminary data estimated a reduction up to $70-80 \%$ in the number of visits in pediatric ED during the COVID-19 outbreak (13). This seems to be confirmed by similar trends observed for adult hospital care services $(14,15)$. According to the results of a retrospective analysis involving 15 Italian Cardiac Intensive Care Units, a substantial decrease in the admission rate for myocardial infarction was shown in the month of March 2020 (13.3 vs 18.9 hospitalizations per day in the preceding year)(15).

The aim of this retrospective study was to provide an insight into the changing pattern of the patient use of a pediatric ED during the SARS-CoV-2 outbreak, comparing the number of accesses and hospitalizations to other control periods.

\section{Materials And Methods}

We retrospectively reviewed medical records from the computerized database system of our Pediatric ED, including all visits performed between 1 March and 30 April, 2020 (COVID) in comparison to the same time intervals in 2018 (Spring 2018 - Sp18) and 2019 (Spring 2019 - Sp19). In order to limit possible confounding effects due to yearly or seasonal changes in total attendances, we also compared data of the two previous Winter (1 January - 29 February 2020, W20; 1 January - 28 February 2019, W19) and Summer periods (1 July - 31 August 2019, Su19; 1 July - 31 August 2018, Su18).

The total and daily number of visits and the hospital admission rate (defined as the number of admissions from the ED relative to the total number of visits) were identified as outcome-relevant patient statistics. We also examined demographic and clinical characteristics of enrolled patients, including initial triage scoring and discharge or admission diagnosis. Two authors extracted data independently.

Both discharge and admission diagnosis were codified according to ICD-9-CM nomenclature(16).

Clinical features and diagnosis were grouped into different categories: 1) children presenting with acute infectious symptoms (e.g. fever, respiratory or gastrointestinal symptoms), 2) traumatic injuries, 3) underlying or chronic disease (e.g. febrile neutropenia in immunosuppressed children, seizures in epileptic children, etc.), 4) surgical urgencies (e.g. acute appendicitis, testicular torsion, etc.), 5) mental health disorders, and 6) other illnesses. Elective and planned hospital admissions were not included in the analysis.

The study was approved by the local Institutional Review Board.

\section{Statistical analysis}

Continuous variables were expressed as mean (SD), while categorical variables were expressed as percentages or frequencies. Differences between groups were evaluated by t-test. Fisher's and $\chi$-square tests were used to compare frequencies and percentages. Linear regression models were used to 
evaluate the trend of daily accesses during the pandemic and in the control periods. A P-value $\leq 0.05$ was considered statistically significant. Statistical analyses were performed using GraphPad Prism version 7.04 for Windows (GraphPad Software, La Jolla California USA, www.graphpad.com).

\section{Results}

A total of 818 children (457 males, $55.9 \%$; mean age $5.6 \pm 4.8$ years) were seen in our pediatric ED during the COVID period. Main clinical and demographic characteristics of the study children are shown in table 1. No significant difference was found between the study population and the control groups (Sp18, Sp19, W19, W20, Su18, Su19) (Supplementary Table 1).

\section{Total number and distribution of triage-scoring categories}

During the COVID outbreak, the total number of visits declined of $73.2 \%$ in comparison to the previous year ( $\mathrm{N}=3051$ ). The proportion of green codes showed a 0.59 -fold decrease $(95 \% \mathrm{Cl} 0.5-0.69)$, while a $1.76(95 \% \mathrm{Cl} 1.38-2.24)$ and 1.46 -fold $(95 \% \mathrm{Cl} 1.2-1.78)$ increase in the proportion of white and yellow codes was observed, respectively (Table 2). No significant change over time was shown for the proportion of red codes (Table 2). Comparisons with Sp18 were similar to those with Sp19 (Table 2). Differences between 2019 and 2018 were also tested and resulted not significant.

Comparison of the total number of ED visits during the COVID outbreak with those observed during W20 and W19 showed a significant reduction (-74.4\% and $-75.4 \%$, respectively), with significant differences in the distribution of the triage scoring (Table 3). Comparisons between 2019 and 2020 winter periods also showed significant changes in the proportion of green (W20: 2399/3202, 74.9\% vs W19: 2619/3334, 78.6\%, p<0.001) and yellow codes (W20: $565 / 3202,17.6 \%$ vs W19: 500/3334, 15\%, $p=0.004)$.

In comparison to the previous summer period, the number of children evaluated in the Pediatric ED decreased of $66.6 \%$ (818 vs 2449 ) (Table 4 ). Green codes showed a 0.66 -fold decrease $(95 \% \mathrm{Cl} 0.55-0.77)$, while yellow codes a 1.67 -fold increase $(95 \% \mathrm{Cl} 1.36-2.05)$. No difference was shown for white and red codes. Comparisons with Su18 were similar (Table 4), and differences between Su19 and Su18 were not significant.

\section{Daily visits and time-trends overview}

A significant decrease in the mean daily number of visits (14.6 $\pm 6.5 /$ day) in comparison to the same time-interval in 2019 (50.9 $\pm 9.6 /$ day, $p<0.001)$ and 2018 (54.4 $\pm 10.8 /$ day, $p<0.001)$ was observed (Figure 1-A). Similarly, comparisons with W20 (54.3 $\pm 11.1 /$ day, $p<0.001)$ and W19 (57.5 $\pm 11.2 /$ day, $p<0.001)$ (Figure 1-B), and with Su19 (39.5 $\pm 8.4 /$ day, $\mathrm{p}<0.001)$ and Su18 $(37.2 \pm 7.5 /$ day, $p<0.001)$ (Figure $1-C)$ confirmed this trend. Differences between seasonal control periods were also tested, and resulted not significant.

\section{Discharge diagnosis}

The distribution of ED discharge diagnosis during the COVID period showed a significant reduction of acute infectious diseases in comparison to all control periods (Table 5). Conversely, a relative increase in traumatic injuries and mental health disorders was observed, whereas accesses of children with chronic or underlying disease remained substantially stable (Table 5). Differences between control periods were tested and no differences were found.

\section{Trends in hospitalizations}

Significant differences were also shown in the number of hospitalizations. The hospital admission rate increased from $3 \%$ (91 hospital admissions out of 3202 ED visits) in the months of March-April 2019 to $7.8 \%(64 / 818)$ in the same time-interval in 2020 ( $p<0.001)$, with a relative 2.7-fold increase (95\%Cl 1.9-3.8). A relative lower number of patients with infectious diseases $(p=0.009)$ were observed compared to the same time-interval in 2019 (Supplementary Table 2). The admission rate during the COVID outbreak resulted also significantly higher than in W20 (2.78, $95 \% \mathrm{Cl} 2-3.85)$, with more cases hospitalized for acute infectious disease than during the COVID period $(p<0.001)$. Comparisons with Sp18 and W19 showed similar results. The admission rate during the COVID outbreak resulted significantly higher than in Su19 (OR 2.42 95\%Cl 1.73-3.4). However, no difference with Su19 and Su18 was shown in the distribution of hospitalization diagnosis.

\section{Discussion}

Compared to the previous two years, this study showed a significant decline in the number of pediatric ED visits during the COVID-19 outbreak and national lockdown, with a substantial increase in the relative rate of hospitalizations. The reduction in ED visits was more prominent for low-acuity diseases (scored as green codes) than for higher triage scores (yellow and red codes).

In recent years, an overcrowding of ED was reported in several countries, and one-fifth of children under 5 years-old had at least one ED access(17). According to a recent Italian report, non-urgent visits (namely, white and green codes) accounted for $27.6 \%$ of all ED users and $58.2 \%$ of total pediatric attendance episodes(18). The decrease in the number of visits observed in our ED during the COVID period was probably due to the restrictive measures. In Italy, schools and sports activities have been closed since 1 March, 2020, so it appears reasonable that acute infections resulted less frequent than usual among children. The drop in the incidence of acute infections might appear in contrast with the increased number of patient visits normally observed during seasonal influenza epidemics(19,20), but currently few cases of COVID-19 among children have been reported(21). As of 27 April, there were almost 200.000 confirmed cases of SARS-CoV-2 infection in Italy, but only $1.2 \%$ of all patients were children(4,22). SARS-CoV-2 affects children less commonly and less severely in comparison to adults (23). Overall, 2.846 Italian children and adolescents below 18 years of age were diagnosed with COVID-19: no death was reported, and 119 out of 2846 cases (4.2\%) were hospitalized (21). 
In our study, a higher proportion of white codes were recorded during the COVID period in comparison to the same time-interval in the two previous years (Sp19 and Sp18) and to winter periods. During the COVID outbreak, outpatient clinics were suspended, therefore all minor procedures, such as daily renewal of burns dressing or removals of stiches, took place in the Pediatric ED. On the other hand, a relative reduction of the proportion of green codes and a contemporary increase of the yellow codes was reported in comparison to all control periods. This could be explained in part by the fact that viral infections (mainly respiratory and gastrointestinal) usually affecting children during winter and early spring seasons(24) decreased due to social distancing, while the number of accesses of children with chronic or underlying disease did not significantly change. However, this trend was observed in comparison to summer periods too, when schools are similarly closed and there are fewer people circulating in urban areas. Therefore, the closure of scholar and recreational activities may not be the only reason for this finding. In 2011, Brousseau et al. conducted a survey on parents' and PCPs' perspectives on the correct utilization of pediatric ED services(12). Parents reported to feel anxious about their children, and they did not consider nonurgent ED visits a violation of the use of healthcare system, as the ED offered firsthand evaluations within the time-frame they desired (12). However, the rapid local and international spread and the ability of this novel Coronovirus to infect a large number of hospital workers generated fears regarding the potential nosocomial transmission of this contagious disease $(25,26)$. Citizens are likely to be more afraid than before to visit healthcare facilities due to the risk of contracting COVID-19, and the use of alternative strategies (e.g., telephone consultation) might have increased. Similarly, during the 2003 SARS outbreak, significant decreases in visits and length of hospital stay in a Canadian pediatric ED were reported(27). This decrease in patient volume together with the government's decision to suspend non-urgent healthcare services encouraged the use of telephone consultation to address mild issues(27).

Incidence of pediatric red codes was not significantly affected during the COVID-19 pandemic. This may be in contrast with a recent case series of 12 children who received delayed hospital care as reported by an Italian Pediatric Hospital Research Network(13). Half of them were admitted to an Intensive Care Unit and four died, and in all cases parents reported avoiding accessing hospital because of fear of infection with SARS-CoV-2(13). This was a preliminary report and no direct comparisons with previous years were available, nor delay in access to care for severely ill children was systematically monitored, therefore it appears speculative to generalize these results. However, concerns have been raised also from reports on adult patients. Recently, a significant increase in mortality due to acute coronary syndrome was observed during the lockdown period, and this was not fully explained by SARS-CoV2 infection alone(15). This observation raises the question of whether the clinical outcome of some of these patients may have been different if they had sought medical attention earlier.

Discharge diagnosis were significantly different among studied periods, in particular a relative increase in the proportion of children presenting with traumatic injuries (including accidental ingestions, burns, foreign body aspiration and bone fractures) was observed during the COVID outbreak. This finding appears in contrast with preliminary data on adult patients, showing a significant reduction in injury-related admissions(28). However, since outdoor activities have been banned from the beginning of the quarantine, children have been forced at home. Domestic accidents represent one of the most frequent causes of morbidity in children under 14 years old, and nearly half of them typically happen during play time(29).

A slightly higher proportion of children with mental health disorders were diagnosed in the pediatric ED during the COVID period. The forced quarantine may worsen existing mental health problems and lead to more cases among children and adolescents because of the unique combination of the public health crisis, social isolation, and economic recession(30). In particular, school closures may be especially disruptive for mental health services of some adolescents with lower family income, who were likely to receive mental health services exclusively from school settings(31).

The rate of hospitalizations also significantly increased, but different patterns of admission diagnosis were demonstrated only in comparison to spring and winter periods, probably due to the lower number of patients with infectious diseases, as previously discussed.

Our study has several limitations. It was a single-centre retrospective analysis, and therefore the generalizability of these findings may be limited to comparable institutions. Moreover, we could not evaluate the possible role of factors influencing people's perceptions and utilization of healthcare facilities, such as family's structure and socioeconomic status, scholarship, distance between the child's house and the ED. However, despite the retrospective design, data were collected prospectively in a standardized way, with detailed clinical and epidemiological information for each patient from hospital software.

In conclusion, during the national lockdown period, our pediatric ED experienced significantly reduced volumes of children presenting with low-acuity problems. This decrease in the number of visits may be due either to a reduction in the incidence of acute infectious diseases and to the fear of the potential nosocomial transmission of COVID-19. However, even if parents may be more afraid to access healthcare facilities, red codes were not likely to be affected and urgent conditions were evaluated as usual. This study not only provides information for future SARS-related public health preparedness policies, it may also provide a foundation for research into strategies other than emergency services to address non-urgent pediatric medical issues.

\section{Declarations}

\section{Author Contribution}

IL and CP conceptualized the study.

IL and MV collected and analyzed data.

IL wrote the first draft of the manuscript and contributed to the final version of the manuscript.

$\mathrm{CP}, \mathrm{MV}, \mathrm{AP}, \mathrm{EP}$ and $\mathrm{PC}$ contributed to the final version of the manuscript 
All authors revised and approved the final version of the manuscript.

\section{Compliance with Ethical Statement:}

Conflict of Interest: All authors have no conflicts of interest to disclose.

\section{Funding Source: None}

Ethical statement: This study was approved by the local Institutional Review Board.

The need for consent from participants was waived by the approving ethics committee.

\section{References}

1. Li Q, Guan X, Wu P, Wang X, Zhou L, Tong Y, et al. Early Transmission Dynamics in Wuhan, China, of Novel Coronavirus-Infected Pneumonia. N Engl J Med. 2020 26;382(13):1199-207.

2. Coronaviridae Study Group of the International Committee on Taxonomy of Viruses. The species Severe acute respiratory syndrome-related coronavirus: classifying 2019-nCoV and naming it SARS-CoV-2. Nat Microbiol. 2020 Apr;5(4):536-44.

3. WHO Director-General's opening remarks at the media briefing on COVID-19 - 11 March 2020 [Internet]. [cited 2020 Mar 30]. Available from: https://www.who.int/dg/speeches/detail/who-director-general-s-opening-remarks-at-the-media-briefing-on-covid-19--11-march-2020

4. Dong E, Du H, Gardner L. An interactive web-based dashboard to track COVID-19 in real time. The Lancet Infectious Diseases [Internet]. 2020 Feb 19 [cited 2020 Mar 30];0(0). Available from: https://www.thelancet.com/journals/laninf/article/PIIS1473-3099(20)30120-1/abstract

5. Sen-Crowe B, McKenney M, Boneva D, Elkbuli A. A state overview of COVID19 spread, interventions and preparedness. Am J Emerg Med [Internet]. 2020 Apr 11 [cited 2020 Apr 27]; Available from: https://www.ncbi.nlm.nih.gov/pmc/articles/PMC7151534/

6. Pan A, Liu L, Wang C, Guo H, Hao X, Wang Q, et al. Association of Public Health Interventions With the Epidemiology of the COVID-19 Outbreak in Wuhan, China. JAMA. 2020 Apr 10;

7. Nicola M, Alsafi Z, Sohrabi C, Kerwan A, Al-Jabir A, losifidis C, et al. The Socio-Economic Implications of the Coronavirus and COVID-19 Pandemic: A Review. Int J Surg. 2020 Apr 16;

8. Lee SY, Khang YH, Lim HK. Impact of the 2015 Middle East Respiratory Syndrome Outbreak on Emergency Care Utilization and Mortality in South Korea. Yonsei Med J. 2019 Aug;60(8):796-803.

9. Paek SH, Kim DK, Lee JH, Kwak YH. The Impact of Middle East Respiratory Syndrome Outbreak on Trends in Emergency Department Utilization Patterns. J Korean Med Sci. 2017 Oct;32(10):1576-80.

10. Carret MLV, Fassa ACG, Domingues MR. Inappropriate use of emergency services: a systematic review of prevalence and associated factors. Cad Saude Publica. 2009 Jan;25(1):7-28.

11. Fieldston ES, Alpern ER, Nadel FM, Shea JA, Alessandrini EA. A qualitative assessment of reasons for nonurgent visits to the emergency department: parent and health professional opinions. Pediatr Emerg Care. 2012 Mar;28(3):220-5.

12. Brousseau DC, Nimmer MR, Yunk NL, Nattinger AB, Greer A. Nonurgent emergency-department care: analysis of parent and primary physician perspectives. Pediatrics. 2011 Feb;127(2):e375-381.

13. Lazzerini M, Barbi E, Apicella A, Marchetti F, Cardinale F, Trobia G. Delayed access or provision of care in Italy resulting from fear of COVID-19. Lancet Child Adolesc Health [Internet]. 2020 Apr 9 [cited 2020 Apr 27]; Available from: https://www.ncbi.nlm.nih.gov/pmc/articles/PMC7146704/

14. Madanelo M, Ferreira C, Nunes-Carneiro D, Pinto A, Rocha MA, Correia J, et al. The impact of the COVID-19 pandemic on the utilization of emergency urological services. BJU Int. 2020 May 14;

15. De Filippo O, D’Ascenzo F, Angelini F, Bocchino PP, Conrotto F, Saglietto A, et al. Reduced Rate of Hospital Admissions for ACS during Covid-19 Outbreak in Northern Italy. New England Journal of Medicine. 2020 Apr 28;0(0):null.

16. Salute M della. II manuale ICD9CM [Internet]. [cited 2020 May 22]. Available from: http://www.salute.gov.it/portale/temi/p2_6.jsp? lingua=italiano\&id=1278\&area=ricoveriOspedalieri\&menu=classificazione

17. Hoot NR, Aronsky D. Systematic review of emergency department crowding: causes, effects, and solutions. Ann Emerg Med. 2008 Aug;52(2):126-36.

18. Vedovetto A, Soriani N, Merlo E, Gregori D. The burden of inappropriate emergency department pediatric visits: why Italy needs an urgent reform. Health Serv Res. 2014 Aug;49(4):1290-305.

19. Proudlove N, Brown C. Winter planning. Seasonal cycles. Health Serv J. 2002 Jan 31;112(5790):24-5.

20. Glaser CA, Gilliam S, Thompson WW, Dassey DE, Waterman SH, Saruwatari M, et al. Medical care capacity for influenza outbreaks, Los Angeles. Emerging Infect Dis. 2002 Jun;8(6):569-74.

21. COVID-19 Integrated Surveillance $\mathrm{B}$ - ISS [Internet]. [cited 2020 Mar 30]. Available from: https://www.iss.it/covid-19-integrated-surveillance

22. Livingston E, Bucher K. Coronavirus Disease 2019 (COVID-19) in Italy. JAMA. 2020 Mar 17;

23. Liguoro I, Pilotto C, Bonanni M, Ferrari ME, Pusiol A, Nocerino A, et al. SARS-COV-2 infection in children and newborns: a systematic review. Eur J Pediatr. 2020 May 18; 
24. Riva B, Clavenna A, Cartabia M, Bortolotti A, Fortino I, Merlino L, et al. Emergency department use by paediatric patients in Lombardy Region, Italy: a population study. BMJ Paediatr Open [Internet]. 2018 May 30 [cited 2020 May 18];2(1). Available from:

https://www.ncbi.nlm.nih.gov/pmc/articles/PMC6014225/

25. Canova V, Lederer Schläpfer H, Piso RJ, Droll A, Fenner L, Hoffmann T, et al. Transmission risk of SARS-CoV-2 to healthcare workers -observational results of a primary care hospital contact tracing. Swiss Med Wkly. 2020 Apr 20;150:w20257.

26. High proportion of healthcare workers with COVID-19 in Italy is a stark warning to the world: protecting nurses and their colleagues must be the number one priority [Internet]. ICN - International Council of Nurses. [cited 2020 Apr 28]. Available from: https://www.icn.ch/news/high-proportionhealthcare-workers-covid-19-italy-stark-warning-world-protecting-nurses-and

27. Boutis K, Stephens D, Lam K, Ungar WJ, Schuh S. The impact of SARS on a tertiary care pediatric emergency department. CMAJ. 2004 Nov 23;171(11):1353-8.

28. Forrester JD, Liou R, Knowlton LM, Jou RM, Spain DA. Impact of shelter-in-place order for COVID-19 on trauma activations: Santa Clara County, California, March 2020. Trauma Surg Acute Care Open. 2020;5(1):e000505.

29. WHO | World report on child injury prevention [Internet]. WHO. World Health Organization; [cited 2020 May 22]. Available from: http://www.who.int/entity/violence_injury_prevention/child/injury/world_report/en/index.html

30. Golberstein E, Wen H, Miller BF. Coronavirus Disease 2019 (COVID-19) and Mental Health for Children and Adolescents. JAMA Pediatr. 2020 Apr 14;

31. Ali MM, West K, Teich JL, Lynch S, Mutter R, Dubenitz J. Utilization of Mental Health Services in Educational Setting by Adolescents in the United States. J Sch Health. 2019;89(5):393-401.

\section{Tables}

Table 1. Demographic, triage scoring and number of admissions of children seen in the Pediatric Emergency Department (ED) in the months of March and April 2020.

\begin{tabular}{|c|c|}
\hline & March-April 2020 \\
\hline $\mathrm{N}$ of patients & 818 \\
\hline Males: n (\%) & $457(55.9 \%)$ \\
\hline Mean age $\pm S D$ (years) & $5.6 \pm 4.8$ \\
\hline \multicolumn{2}{|l|}{ Triage scoring: $\mathrm{n}(\%)$} \\
\hline - White & $103(12.6 \%)$ \\
\hline - $\quad$ Green & $540(66 \%)$ \\
\hline - Yellow & 169 (20.7\%) \\
\hline - $\quad$ Red & $6(0.7 \%)$ \\
\hline $\mathrm{N}$ of Admission: $\mathrm{n}(\%)$ & $64(7.8 \%)$ \\
\hline - General Pediatric Ward & $59(92 \%)$ \\
\hline - $\quad$ Neonatal Intensive Care Unit & $3(5 \%)$ \\
\hline - Intensive Care Unit & $1(1.5 \%)$ \\
\hline - $\quad$ Surgical Ward & $1(1.5 \%)$ \\
\hline
\end{tabular}

Table 2. Total number and distribution of triage-scoring categories of children seen in the Pediatric Emergency Department (ED) during the months of March-April 2020 (COVID), compared to the same time-intervals in 2019 (Sp19) and 2018 (Sp18). 


\begin{tabular}{|c|c|c|c|c|c|c|}
\hline & COVID & Sp19 & Sp18 & $p$ & COVID vs Sp19 & COVID vs Sp18 \\
\hline & $N=818$ & $N=3051$ & $N=3266$ & & OR (95\% Cl) & OR $(95 \% \mathrm{Cl})$ \\
\hline \multirow[t]{2}{*}{ White } & 103 & 231 & 287 & $<0.001$ & $1.76(1.38-2.24)$ & $1.49(1.17-1.88)$ \\
\hline & $12.6 \%$ & $7.6 \%$ & $8.8 \%$ & & & \\
\hline \multirow[t]{2}{*}{ Green } & 540 & 2340 & 2524 & $<0.001$ & $0.59(0.50-0.69)$ & $0.56(0.47-67)$ \\
\hline & $66 \%$ & $76.7 \%$ & $77.3 \%$ & & & \\
\hline \multirow[t]{2}{*}{ Yellow } & 169 & 461 & 440 & $<0.001$ & $1.46(1.20-1.78)$ & $1.67(1.37-2.03)$ \\
\hline & $20.7 \%$ & $15 \%$ & $13.5 \%$ & & & \\
\hline \multirow[t]{2}{*}{ Red } & 6 & 19 & 15 & 0.54 & $1.18(0.5-2.94)$ & $1.6(0.64-4)$ \\
\hline & $0.7 \%$ & $0.6 \%$ & $0.5 \%$ & & & \\
\hline
\end{tabular}

Differences between groups were tested by Fisher's and $\chi$-square tests

Table 3. The total number and distribution of triage-scoring categories of children seen in the Pediatric Emergency Department (ED) during the months of March-April 2020 (COVID), compared to winter months (January-February) 2020 (W20) and 2019 (W19).

\begin{tabular}{|lllllll|}
\hline & $\begin{array}{l}\text { COVID } \\
\text { N=818 }\end{array}$ & $\begin{array}{l}\text { W20 } \\
\text { N=3202 }\end{array}$ & $\begin{array}{l}\text { W19 } \\
\text { N=3334 }\end{array}$ & $p$ & $\begin{array}{l}\text { COVID vs W20 } \\
\text { OR (95\%Cl) }\end{array}$ & $\begin{array}{l}\text { COVID vs W19 } \\
\text { OR (95\%Cl) }\end{array}$ \\
\hline White & 103 & 224 & 191 & $<0.001$ & $1.9(1.49-2.45)$ & 2.37 (1.17-1.88) \\
& $12.6 \%$ & $7 \%$ & $5.7 \%$ & & & \\
\hline Green & 540 & 2399 & 2619 & $<0.001$ & $\mathbf{0 . 6 5}(\mathbf{0 . 5 5 - 0 . 7 7 )}$ & $\mathbf{0 . 5 3}(\mathbf{0 . 4 5 - 0 . 6 2 )}$ \\
& $66 \%$ & $74.9 \%$ & $78.6 \%$ & & & \\
Yellow & 169 & 565 & 500 & $<0.001$ & $\mathbf{1 . 2 2}(\mathbf{1 . 1}-1.47)$ & $\mathbf{1 . 4 7}(\mathbf{1 . 2 2 - 1 . 7 9 )}$ \\
& $20.7 \%$ & $17.6 \%$ & $15 \%$ & & & \\
\hline Red & 6 & 14 & 24 & 0.29 & $1.68(0.67-4.37)$ & $1.02(0.44-2.37)$ \\
& $0.7 \%$ & $0.4 \%$ & $0.7 \%$ & & & \\
\hline
\end{tabular}

Differences between groups were tested by Fisher's and $\chi$-square tests

Table 4. Total number and distribution of triage-scoring categories of children seen in the Pediatric Emergency Department (ED) during the months of March-April 2020 (COVID), compared to summer months (July-August) 2019 (Su19) and 2018 (Su18).

\begin{tabular}{|c|c|c|c|c|c|c|}
\hline & COVID & Su19 & Su18 & $p$ & COVID vs Su19 & COVID vs Su18 \\
\hline & $N=818$ & $N=2449$ & $\mathrm{~N}=2244$ & & OR $(95 \% \mathrm{Cl})$ & OR $(95 \% \mathrm{Cl})$ \\
\hline \multirow[t]{2}{*}{ White } & 103 & 276 & 297 & 0.167 & $1.1(0.89-1.14)$ & $0.94(0.74-1.2)$ \\
\hline & $12.6 \%$ & $11.3 \%$ & $13.2 \%$ & & & \\
\hline \multirow[t]{2}{*}{ Green } & 540 & 1830 & 1699 & $<0.001$ & $0.66(0.55-0.77)$ & $0.67(0.56-0.79)$ \\
\hline & $66 \%$ & $74.7 \%$ & $74.4 \%$ & & & \\
\hline \multirow[t]{2}{*}{ Yellow } & 169 & 330 & 271 & $<0.001$ & $1.67(1.36-2.05)$ & $1.89(1.53-2.34)$ \\
\hline & $20.7 \%$ & $13.5 \%$ & $12.1 \%$ & & & \\
\hline \multirow[t]{2}{*}{ Red } & 6 & 13 & 7 & 0.273 & $1.38(0.5-3.5)$ & $2.36(0.79-6.43)$ \\
\hline & $0.7 \%$ & $0.5 \%$ & $0.3 \%$ & & & \\
\hline
\end{tabular}

Differences between groups were tested by Fisher's and $\chi$-square tests 
Table 5. Distribution of discharge diagnosis in children who were seen in the Pediatric Emergency Department (ED) in comparison to the COVID period (March-April 2020).

\begin{tabular}{|c|c|c|c|c|c|c|c|c|c|c|c|c|c|}
\hline & COVID & Sp19 & $p^{*}$ & Sp18 & $p^{*}$ & W20 & $p^{*}$ & W19 & $p^{*}$ & Su19 & $p^{*}$ & Su18 & $p^{*}$ \\
\hline & $\mathrm{N}=796$ & $\mathrm{~N}=3094$ & & $\mathrm{~N}=3388$ & & $\mathrm{~N}=3343$ & & $\mathrm{~N}=3498$ & & $\mathrm{~N}=2518$ & & $\mathrm{~N}=2346$ & \\
\hline $\begin{array}{l}\text { Acute } \\
\text { infectious } \\
\text { diseases }\end{array}$ & $\begin{array}{l}250 \\
(31 \%) \\
\downarrow\end{array}$ & $\begin{array}{l}1580 \\
(51 \%)\end{array}$ & $<0.001$ & $\begin{array}{l}1657 \\
(49 \%)\end{array}$ & $<0.001$ & $\begin{array}{l}1915 \\
(57 \%)\end{array}$ & $<0.001$ & $\begin{array}{l}2055 \\
(58 \%)\end{array}$ & $<0.001$ & $\begin{array}{l}1121 \\
(44 \%)\end{array}$ & $<0.001$ & $\begin{array}{l}1002 \\
(43 \%)\end{array}$ & $<0.001$ \\
\hline $\begin{array}{l}\text { Traumatic } \\
\text { injuries }\end{array}$ & $\begin{array}{l}318 \\
(40 \%) \\
\uparrow\end{array}$ & $\begin{array}{l}740 \\
(24 \%)\end{array}$ & $<0.001$ & $\begin{array}{l}865 \\
(26 \%)\end{array}$ & $<0.001$ & $\begin{array}{l}646 \\
(19 \%)\end{array}$ & $<0.001$ & $\begin{array}{l}670 \\
(19 \%)\end{array}$ & $<0.001$ & $\begin{array}{l}702 \\
(28 \%)\end{array}$ & $<0.001$ & $\begin{array}{l}779 \\
(33 \%)\end{array}$ & $<0.001$ \\
\hline $\begin{array}{l}\text { Underlying } \\
\text { diseases }\end{array}$ & $\begin{array}{l}27 \\
(3 \%)=\end{array}$ & $\begin{array}{l}85 \\
(3 \%)\end{array}$ & 0.342 & $\begin{array}{l}99 \\
(3 \%)\end{array}$ & 0.489 & $\begin{array}{l}59 \\
(2 \%)\end{array}$ & 0.08 & $\begin{array}{l}87 \\
(3 \%)\end{array}$ & 0.178 & $\begin{array}{l}84 \\
(3 \%)\end{array}$ & 0.91 & $\begin{array}{l}40 \\
(2 \%)\end{array}$ & 0.06 \\
\hline $\begin{array}{l}\text { Mental } \\
\text { health } \\
\text { disorders }\end{array}$ & $\begin{array}{l}16 \\
(2 \%) \uparrow\end{array}$ & $\begin{array}{l}24 \\
(0.8 \%)\end{array}$ & 0.005 & $\begin{array}{l}28 \\
(0.8 \%)\end{array}$ & 0.006 & $\begin{array}{l}13 \\
(0.4 \%)\end{array}$ & $<0.001$ & $\begin{array}{l}14 \\
(0.4 \%)\end{array}$ & $<0.001$ & $\begin{array}{l}15 \\
(0.6 \%)\end{array}$ & 0.001 & $\begin{array}{l}9 \\
(0.4 \%)\end{array}$ & $<0.001$ \\
\hline $\begin{array}{l}\text { Other } \\
\text { illnesses }\end{array}$ & $\begin{array}{l}185 \\
(24 \%) \\
=\end{array}$ & $\begin{array}{l}665 \\
(21 \%)\end{array}$ & 0.29 & $\begin{array}{l}739 \\
(22 \%)\end{array}$ & 0.393 & $\begin{array}{l}710 \\
(21 \%)\end{array}$ & 0.135 & $\begin{array}{l}672 \\
(19 \%)\end{array}$ & 0.06 & $\begin{array}{l}596 \\
(24 \%)\end{array}$ & 0.848 & $\begin{array}{l}516 \\
(22 \%)\end{array}$ & 0.46 \\
\hline
\end{tabular}

Differences between groups were tested by Fisher's and $\chi$-square tests. * vs COVID period

Figures

(A)

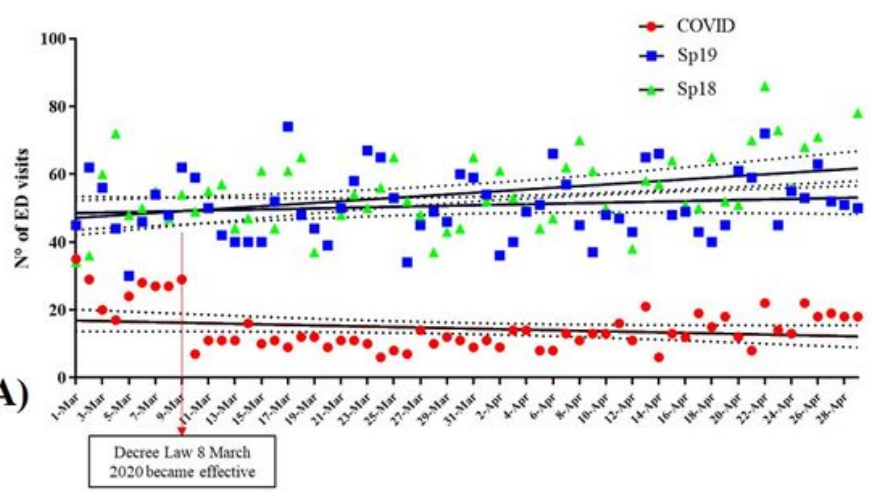

(C)

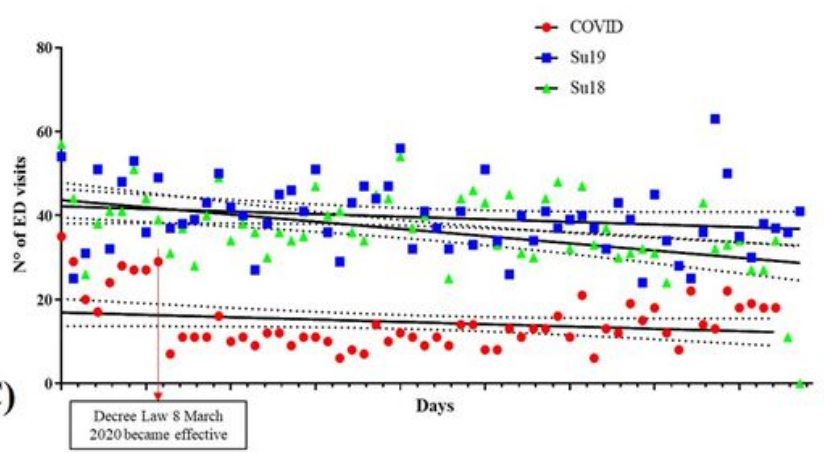

(B)

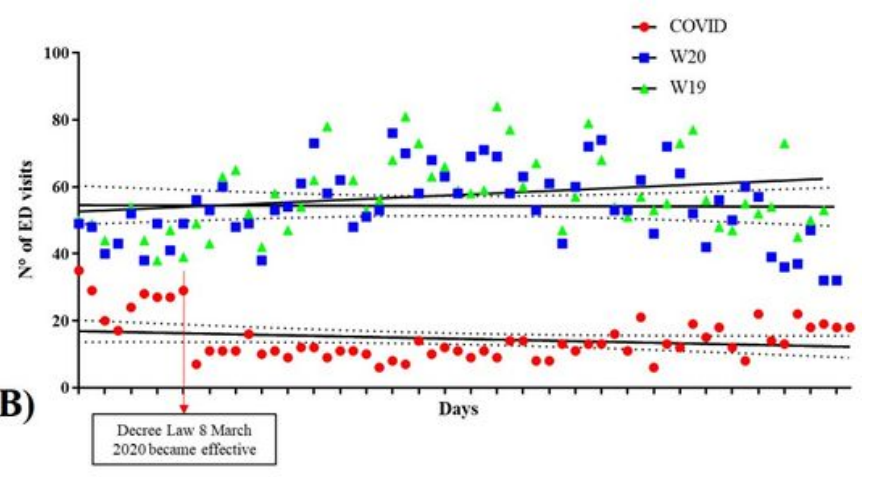

Figure 1

Linear regression models comparing the trend in the number of daily visits in the Pediatric Emergency Department (ED) during the COVID-19 outbreak (March-April 2020, red line) and the same time-intervals in 2019 and 2018 (A), January-February 2020 and 2019 (B), July-August 2019 and 2018 (C). Solid lines represent the linear regression lines and dashed lines represent the corresponding $95 \% \mathrm{Cl}$.

\section{Supplementary Files}

This is a list of supplementary files associated with this preprint. Click to download.

- SupplementaryTable1.docx 
- SupplementaryTable2.docx

Page 9/9 